\title{
Simulation Precision and the Human Factor
}

\author{
Joni Klüss ${ }^{1}$, Andrii Bichik ${ }^{1}$, Ammar Arshad ${ }^{1}$, Jan Strandberg ${ }^{1}$, Syed Kazmi ${ }^{1}$, Mika Laiho ${ }^{1}$, \\ Tuomas Stark $^{1}$, Jay Panchal ${ }^{1}$, Bilal Ahmad ${ }^{1}$, Kenneth Väkeväinen ${ }^{2}$ \\ ${ }^{1}$ Aalto University, Department of Electrical Engineering and Automation, Finland \\ ${ }^{2}$ Ensto Finland Oy, Finland
}

\begin{abstract}
Computer simulations are a powerful tool to support the design and development of electrical components and equipment. However, simulations are configured by a user, thus inevitably incorporating the human factor and potentially leading to divergence in results. To assess this degree of variance and thus the role of the user, 10 participants were asked to simulate the same medium voltage porcelain pin insulator using FEM software. Boundary conditions and materials were fixed. However, participants were able to define the geometry and details of the pin insulator by any means at their disposal. The varying skills of the participants resulted in geometries ranging from highly detailed complex models to rougher approximations. A CAD model provided by the pin insulator manufacturer is used as a reference. To quantify the extent of divergence, electric field intensity values in selected critical areas of the geometry are compared. This study presents the influence of the human factor and investigates the requirements for reliable simulation, i.e., how detailed does a model have to be to produce reliable information. The findings of this study can be used to save time and focus efforts on pertinent aspects in simulations.
\end{abstract}

\section{Introduction}

With advances in computational hardware and software, simulations have become ever more popular for designing high voltage systems and components. However, the accuracy (and thus, validity) of the simulated information is influenced by the user - the human factor. Computers do not interpret human intent, but rather human input. To investigate the degree of divergence resulting from variations between users, 10 participants were given the same task with fixed parameters. The participants consisted of users with no prior experience in simulation, members with CAD experience (i.e., drawing), and members previously familiar with the software.

This investigation assesses only the influence of the user on simulated results and does not evaluate the performance of the pin insulator itself. The purpose is to define the influential factors related to data integrity, thus improving efficient time utilization and workload along with improving validity of simulated results.

\section{Task description}

All participants were asked to simulate the pin insulator configuration displayed in Fig 1. Each participant was provided with a pin insulator sample for closer inspection. No restrictions concerning the simplicity or complexity of the design were specified. The participants were asked to determine the dimensions of the insulator by any means at their disposal. To ensure comparability between the models, critical parameters were provided, including material properties (Table 1), dimensions of the pin (rod), and conductor (wire) diameter. The participants were all provided with COMSOL Multiphysics software (version 5) and instructed to create a three-dimensional geometry using the Electrostatics interface in the AC/DC module and a stationary study. Ground and electric potential boundary conditions were fixed but mesh size could be freely selected. Participants needed to produce a functional simulation, but did not perform any analysis of the results. All comparisons have been carried out by the main author.
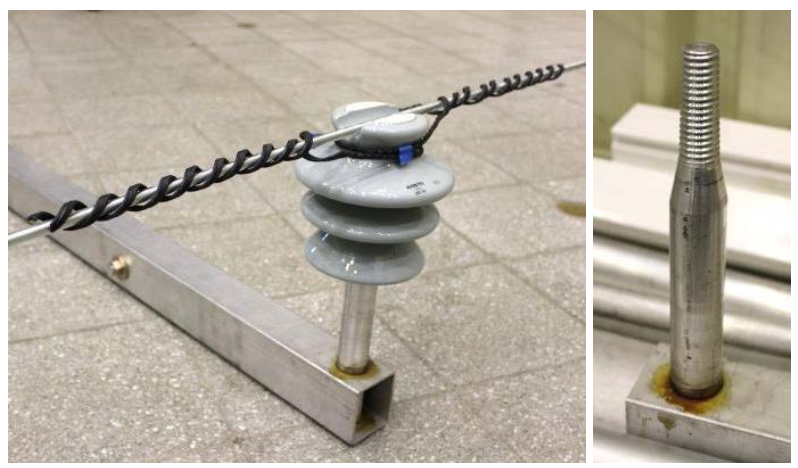

Fig. 1 - Pin insulator configuration provided to the participants (crossarm and distance to ground could be disregarded).

Table 1 - Materials and approximate values for relative permittivity utilized in the simulations.

\begin{tabular}{|l|c|l|}
\hline \multicolumn{1}{|c|}{ Material } & $\begin{array}{c}\text { Relative } \\
\text { permittivity } \\
\varepsilon_{\mathrm{r}}\end{array}$ & \multicolumn{1}{c|}{ Description } \\
\hline Aluminum & 1 & All conductors (including tie) \\
\hline Porcelain & 6 & Insulator \\
\hline Epoxy resin & 4 & Pin cavity walls, threads \\
\hline Filler (hemp) & 2 & In between threads (optional) \\
\hline Cork & 1.5 & Bottom of pin insert \\
\hline Air & 1 & Surroundings \\
\hline
\end{tabular}




\section{Model geometries and simulation parameters}

The insulator manufacturer's CAD drawing of the design was utilized as a reference and was imported into the simulation software. This model was originally intended only for visualization and not optimized for simulation. Small modifications were needed to make the model functional. Reference dimensions are shown in Fig. 2 (distance D was not specified in the product's data sheet).

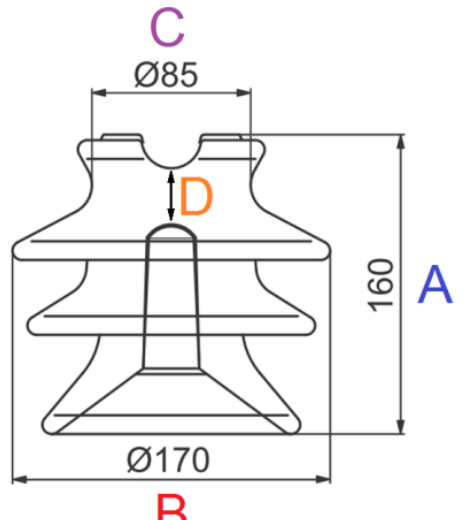

Fig. 2 - Dimensions of reference pin insulator [1].

Despite being provided equivalent pin insulator samples, dimensions of each participant's simulation model varied as is evident in Fig. 3.
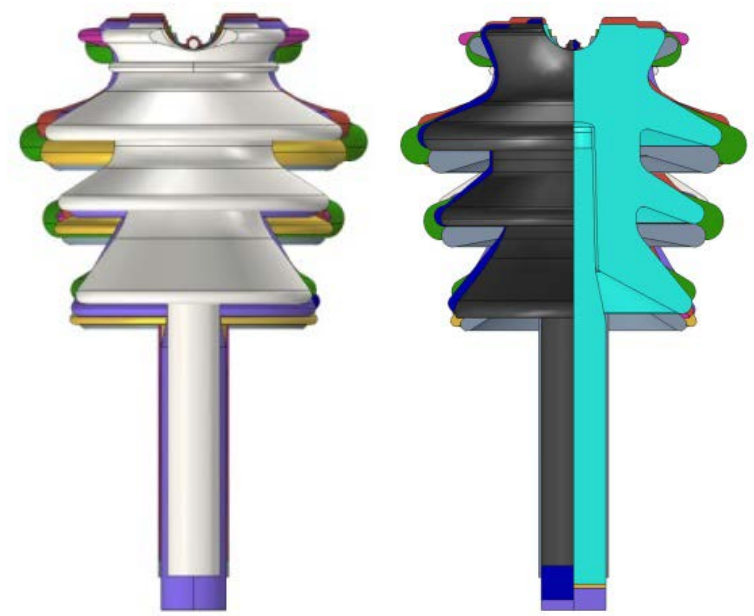

Fig. 3 - Participant's simulation models (reference in white).

As displayed in Table 2, the relative size of the entire model (including pin and disregarding surrounding air) ranged from $92-107 \%$. The height (A) of the insulator was measured rather consistently, but nevertheless consistently larger than the reference height. No model was completely comparable with the reference. Each model either diverged in one or more measures (height, width, thickness). In addition to differing dimensions of the porcelain insulator, the pin cavity varied considerably. Some models included a small air pocket while others fully inserted the pin so that only cork remained between the metal pin and porcelain insulator.
Two models implemented the conductor tie. Only one model included pin threads and thread filler.

Table 2 - Dimensions of simulation models.

\begin{tabular}{|c|c|c|c|c|c|}
\hline Model & $\begin{array}{c}\text { Relative } \\
\text { size } \\
{[\%]}\end{array}$ & $\begin{array}{c}\text { Insulator } \\
\text { height } \\
\text { A } \\
{[\mathrm{m}]}\end{array}$ & $\begin{array}{c}\text { Insulator } \\
\text { diameter } \\
\mathbf{B} \\
{[\mathrm{m}]}\end{array}$ & $\begin{array}{c}\text { Neck } \\
\text { width } \\
\mathbf{C} \\
{[\mathrm{m}]}\end{array}$ & $\begin{array}{c}\text { Porcelain } \\
\text { thickness } \\
\mathrm{D} \\
{[\mathrm{m}]}\end{array}$ \\
\hline REF & $\mathbf{1 0 0}$ & $\mathbf{0 . 1 6 0}$ & $\mathbf{0 . 1 7 0}$ & $\mathbf{0 . 0 8 5}$ & $\mathbf{0 . 0 3 1}$ \\
\hline M1 & 99 & 0.169 & 0.173 & 0.086 & 0.032 \\
\hline M2 & 106 & 0.168 & 0.179 & 0.090 & 0.063 \\
\hline M3 & 102 & 0.166 & 0.170 & 0.085 & 0.041 \\
\hline M4 & 98 & 0.169 & 0.167 & 0.060 & 0.040 \\
\hline M5 & 98 & 0.157 & 0.198 & 0.054 & 0.038 \\
\hline M6 & 92 & 0.170 & 0.177 & 0.070 & 0.061 \\
\hline M7 & 99 & 0.173 & 0.179 & 0.083 & 0.037 \\
\hline M8 & 103 & 0.175 & 0.175 & 0.084 & 0.043 \\
\hline M9 & 107 & 0.170 & 0.158 & 0.091 & 0.047 \\
\hline avg & & $\mathbf{0 . 1 6 8}$ & $\mathbf{0 . 1 7 5}$ & $\mathbf{0 . 0 7 9}$ & $\mathbf{0 . 0 4 3}$ \\
\hline std & & 0.005 & 0.010 & 0.012 & 0.010 \\
\hline
\end{tabular}

Not only do the varying physical properties of the model influence results, but the selected simulation parameters also impact the outcome. Table 3 presents the mesh properties for each model, including their rotational degree (i.e., $360^{\circ}=$ full geometry, $180^{\circ}=$ half geometry, and $90^{\circ}=1 / 4$ geometry). As the model allows for axial symmetry, participants could freely select to simulate only a portion of the geometry.

Table 3 - Mesh properties of the simulation models.

\begin{tabular}{|c|c|c|c|c|c|c|}
\hline Model & $\begin{array}{c}\text { Rot. } \\
\text { deg. }\end{array}$ & Mesh & $\begin{array}{c}\text { Mesh } \\
\text { vol. } \\
{\left[\mathrm{m}^{3}\right]}\end{array}$ & $\begin{array}{c}\text { Num. of } \\
\text { elements }\end{array}$ & Min $^{1}$ & Avg \\
\hline REF & $360^{\circ}$ & finer & 0.70 & 392516 & 0.00004 & 0.72 \\
\hline MI & $180^{\circ}$ & finer & 0.29 & 145049 & 0.04955 & 0.71 \\
\hline M2 & $90^{\circ}$ & fine & 1.50 & 387384 & 0.00380 & 0.69 \\
\hline M3 & $180^{\circ}$ & norm. & 0.03 & 75094 & 0.00016 & 0.65 \\
\hline M4 & $180^{\circ}$ & norm. & 0.01 & 57855 & 0.00287 & 0.68 \\
\hline M5 & $180^{\circ}$ & norm. & 0.01 & 62973 & 0.00002 & 0.68 \\
\hline M6 & $180^{\circ}$ & finer & 0.02 & 394500 & 0.00001 & 0.71 \\
\hline M7 & $180^{\circ}$ & $\begin{array}{c}\text { extra } \\
\text { fine }\end{array}$ & 0.03 & 2632370 & $1.8 \cdot 10^{-8}$ & 0.73 \\
\hline M8 & $180^{\circ}$ & finer & 1.00 & 316930 & 0.09555 & 0.73 \\
\hline M9 & $90^{\circ}$ & coarse & 0.03 & 44337 & $2.5 \cdot 10^{-11}$ & 0.55 \\
\hline
\end{tabular}

minimum element quality $>0.1$ recommended.

The mesh volume in Table 3 includes the surrounding air around the pin insulator. Hence, model M8 and M2 with considerably larger mesh volumes implement a much larger surrounding air while still utilizing the same size insulator. Volume does not directly relate to simulation quality. The minimum element quality value is recommended to be greater than 0.1 [2]. Based on this recommendation, only model M8 is close to fulfilling the minimum quality criteria for mesh size. Although M7 utilizes a significant number of elements (Fig. 4 right, mesh = extra fine $=2632370$ elements), the minimum element quality is poor. The diverging dimensions of the models along with varying mesh parameters are expected to result in varying simulation results. 

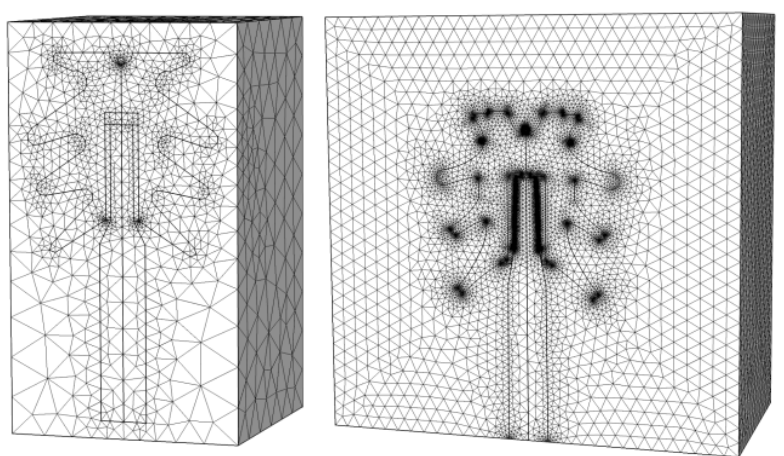

Fig. 4 - Comparison between meshes of model M4 (left, 57855 elements) and M7 (right, 2632370 elements).

\section{Results}

In all models, the conductor (and conductor tie) were assigned $U=125 \mathrm{kV}$ (electric potential $V_{0}$ ). This value corresponds to lightning impulse test voltages and was selected to ease visualization of results (i.e., high voltage stress augments electric field concentration). The rod was grounded (electric potential $V=0$ ). Critical locations (areas of highest electric field concentration) were selected for comparison. These include (Fig. 5, Table 4):

- A: conductor (surrounding air and porcelain below point of contact)

- B: conductor tie (surrounding air and porcelain below point of contact)

- $\quad \mathbf{C}$ : pin cavity (air pocket, porcelain surrounding the cavity, cork protecting the porcelain, epoxy threads)

- D: pin entrance (air around entrance, epoxy, and filler in between rod and epoxy threads).

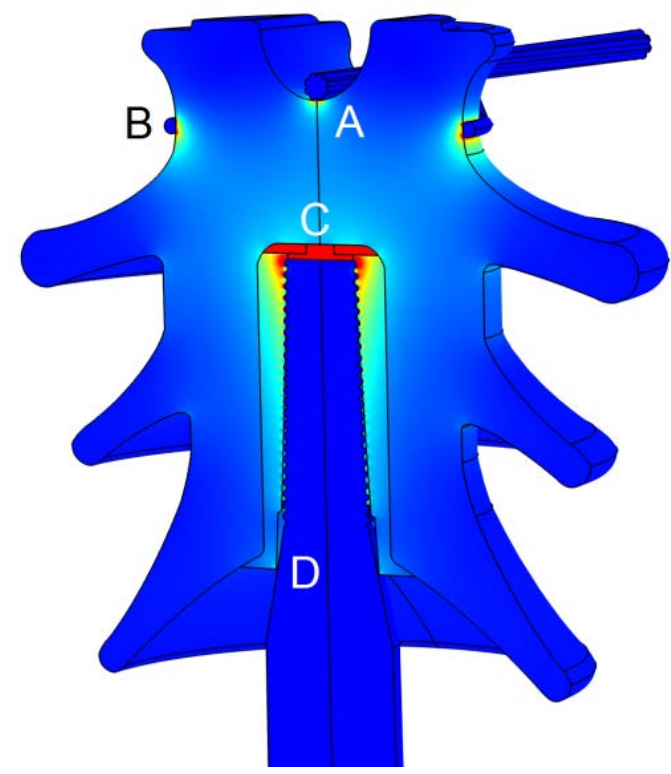

Fig. 5 - Critical points under investigation: electric field around conductor (A), around conductor tie (B), around pin cavity (C) and pin insert (D). Highest electric field intensity visualized by red color (surrounding air not included in this image).
As to be expected, the highest electric field concentration was observed in the air surrounding (under) the high voltage conductor with the exception of M8 where exceptionally high electric field values were simulated in the cork due to the differing pin cavity format in this particular model (Fig. 6).
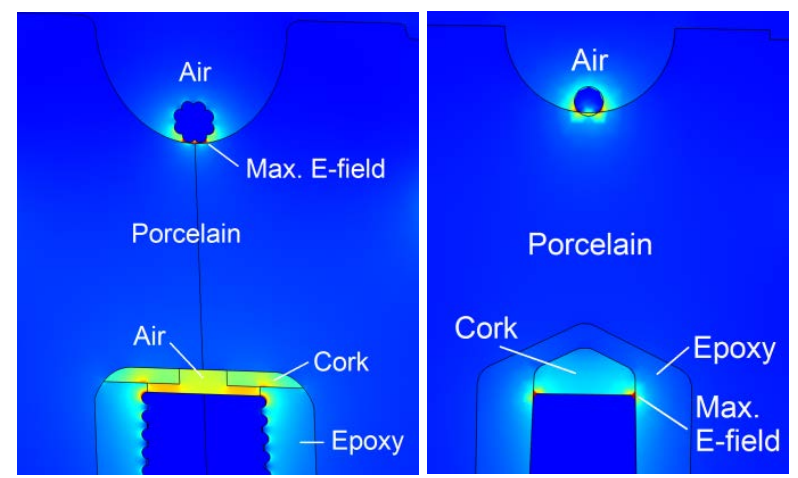

Fig. 6 - Diverging insulator design in model M8 (right) compared to M7 (left).

Although the other models all identified the surrounding air as having the largest electric field intensity, each model provided a fluctuating value ranging from $22 \mathrm{kV} / \mathrm{mm}$ up to $80 \mathrm{kV} / \mathrm{mm}$. This variation is influenced by the different contacts between the conductor and porcelain surface in each model. The reference model has a small air gap in between the conductor and porcelain surface. M1, M2, and M9 have a single contact point (line). M3, M4, M5, and M8 have a larger contact area between conductor and porcelain ranging from $0.09 \cdot 10^{-9}$ to $1 \cdot 10^{-9} \mathrm{~m}^{2}$. M6 has its conductor immerged into the porcelain forming a $0.09 \cdot 10^{-9} \mathrm{~m}^{2}$ surface contact. M7 implements a twisted stranded conductor which has multiple contact points with the porcelain. The small angles formed by these contacts create localized areas of high electric field intensity which is defined by the mesh size of each model. Interestingly, M3, M4, M5, M6, and M8 all utilize a surface area contact but still produce highly divergent field values for this region (Table 4, Point $A_{\text {air }}$ ). From these models, M3 is the only model that includes an air pocket in the pin cavity. M4 and M5 are relatively similar models but still output differing electric field values of $80 \mathrm{kV} / \mathrm{mm}$ and $22 \mathrm{kV} / \mathrm{mm}$ respectively in this area.

Considering the purpose of a simulation such as this, the user would mainly be interested in simulating the withstand strength of the porcelain material. Exceeding critical electric field values in air will result in flashover (self-restoring discharge) whereas exceeding the dielectric strength of porcelain will result in puncturing of the insulator and thereby permanent failure. The porcelain is stressed mainly at three locations - point $\mathrm{A}_{\text {porcelain }}$ under the conductor, point $\mathrm{B}_{\text {porcelain }}$ under the conductor tie, and point $\mathrm{C}_{\text {porcealain }}$ in the proximity of the grounded pin in the pin cavity. Only two models (REF and M7) included the conductor tie in the simulation. This inclusion has a significant influence on the field distribution in the porcelain. 


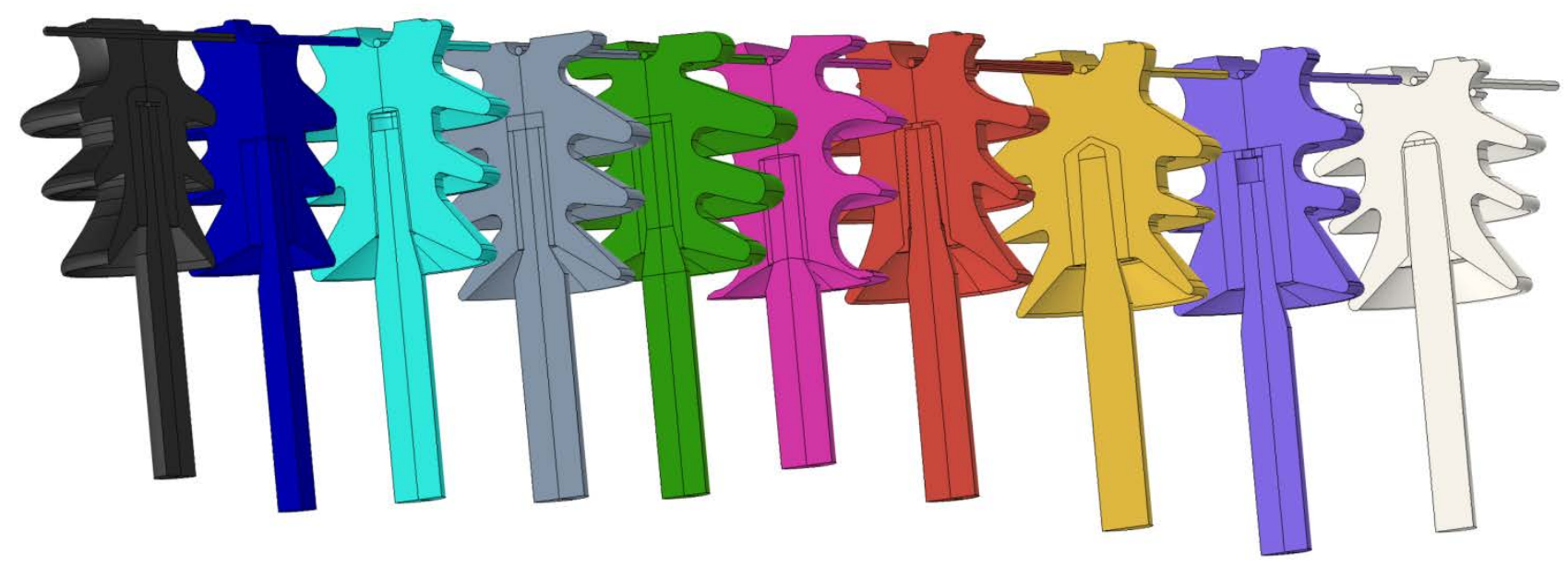

Fig. 7 - Model geometries. From left to right: M1, M2, M3, M4, M5, M6, M7, M8, M9, and reference model in white.

Table 4 - Electric field strength at critical locations (critical locations identified in Fig 5). The bold values are manually derived values from the simulation results. The software can calculate precise values for maximum electric field on the surface/interface of a material (surface max) and maximum values within a material volume (volume max).

\begin{tabular}{|c|c|c|c|c|c|c|c|c|c|c|c|}
\hline & \multicolumn{11}{|c|}{ Maximum Electric Field [kV/mm]: } \\
\hline & \multicolumn{2}{|c|}{$\begin{array}{l}\text { Point A } \\
\text { Conductor }\end{array}$} & \multicolumn{2}{|c|}{$\begin{array}{c}\text { Point B } \\
\text { Conductor tie }\end{array}$} & \multicolumn{4}{|c|}{$\begin{array}{c}\text { Point C } \\
\text { Pin cavity }\end{array}$} & \multicolumn{3}{|c|}{$\begin{array}{c}\text { Point D } \\
\text { Pin entrance }\end{array}$} \\
\hline & $\mathbf{A}_{\text {air }}$ & $A_{\text {porcelain }}$ & $\mathbf{B}_{\text {air }}$ & $\mathbf{B}_{\text {porcelain }}$ & $\mathrm{C}_{\text {air }}$ & $\mathrm{C}_{\text {porcelain }}$ & $\mathrm{C}_{\text {cork }}$ & $\mathrm{C}_{\text {epoxy }}$ & $\mathbf{D}_{\text {air }}$ & $\mathbf{D}_{\text {epoxy }}$ & $\mathbf{D}_{\text {filler }}$ \\
\hline REF & $\begin{array}{c}\mathbf{5 0 - 6 7} \\
(34 / 148)\end{array}$ & $\begin{array}{c}6.5 \\
(34 /-)\end{array}$ & $\begin{array}{c}\mathbf{2 8} \\
(25 /-)\end{array}$ & $\begin{array}{l}\mathbf{1 2 - 1 6} \\
(25 /-)\end{array}$ & $\begin{array}{c}\mathbf{1 1} \\
(11 / 12)\end{array}$ & $\begin{array}{c}6.7 \\
(11 /-)\end{array}$ & $\begin{array}{c}\mathbf{1 5} \\
(13 / 16)\end{array}$ & $\begin{array}{c}\mathbf{1 6 . 8} \\
(13 / 17)\end{array}$ & $\begin{array}{c}1.3 \\
(2.1 /-)\end{array}$ & $\begin{array}{c}1.3-1.6 \\
(2.1 /-)\end{array}$ & \\
\hline M1 & $\begin{array}{c}70 \\
(52 / 89)\end{array}$ & $\begin{array}{c}14.5 \\
(52 / 16)\end{array}$ & & & $\begin{array}{c}\mathbf{1 1} \\
(11 / 11)\end{array}$ & $\begin{array}{c}1.3 \\
(1.7 /-)\end{array}$ & $\begin{array}{c}\mathbf{1 6} \\
(17 / 20)\end{array}$ & $\begin{array}{c}\mathbf{1 0 . 8} \\
(16 / 12)\end{array}$ & $\begin{array}{l}1.95 \\
(2 /-)\end{array}$ & $\begin{array}{l}1.95 \\
(2 /-)\end{array}$ & \\
\hline M2 & $\begin{array}{c}\mathbf{5 7} \\
(35 / 63)\end{array}$ & $\begin{array}{c}\mathbf{9 . 8} \\
(35 / 10)\end{array}$ & & & & $\begin{array}{c}2.9 \\
(8 /-)\end{array}$ & $\begin{array}{c}\mathbf{1 7 . 4} \\
(17 / 22)\end{array}$ & $\begin{array}{c}9 \\
(16 / 10)\end{array}$ & $\begin{array}{c}\mathbf{2 . 1} \\
(2.3 /-)\end{array}$ & $\begin{array}{c}\mathbf{2 . 0} \\
(2.3 /-)\end{array}$ & \\
\hline M3 & $\begin{array}{c}67 \\
(70 / 74)\end{array}$ & $\begin{array}{c}\mathbf{1 7} \\
(52 / 30)\end{array}$ & & & $\begin{array}{c}\mathbf{1 2} \\
(19 / 14)\end{array}$ & $\begin{array}{c}\mathbf{2 . 6} \\
(3.5 /-)\end{array}$ & $\begin{array}{c}3.4 \\
(4 / 4)\end{array}$ & $\begin{array}{c}\mathbf{1 5 - 1 9} \\
(19 / 36)\end{array}$ & $\begin{array}{c}4.1 \\
(6.3 /-)\end{array}$ & $\begin{array}{c}\mathbf{2 . 8} \\
(6.3 /-)\end{array}$ & \\
\hline M4 & $\begin{array}{c}\mathbf{8 0} \\
(80 / 83) \\
\end{array}$ & $\begin{array}{c}\mathbf{1 7 . 6} \\
(51 / 19) \\
\end{array}$ & & & & $\begin{array}{c}2.0 \\
(2.3 /-)\end{array}$ & $\begin{array}{c}\mathbf{1 0} \\
(13 / 17)\end{array}$ & $\begin{array}{l}\mathbf{8 . 5}-10 \\
(13 / 11)\end{array}$ & $\begin{array}{c}1.2 \\
(1 /-)\end{array}$ & $\begin{array}{c}1.0 \\
(1.0 /-)\end{array}$ & \\
\hline M5 & $\begin{array}{c}22 \\
(20 / 29)\end{array}$ & $\begin{array}{c}13 \\
(20 / 23)\end{array}$ & & & & $\begin{array}{c}2.7 \\
(4.5 /-)\end{array}$ & $\begin{array}{c}12 \\
(13 / 14)\end{array}$ & $\begin{array}{c}\mathbf{8 . 9} \\
(11 / 9)\end{array}$ & $\begin{array}{c}1.7 \\
(2.7 /-)\end{array}$ & $\begin{array}{c}\mathbf{1 . 7 - 2 . 0} \\
(2.7 /-)\end{array}$ & \\
\hline M6 & $\begin{array}{c}\mathbf{4 0} \\
(40 / 44)\end{array}$ & $\begin{array}{c}18 \\
(34 / 24)\end{array}$ & & & & $\begin{array}{c}3.4 \\
(12 /-)\end{array}$ & $\begin{array}{c}31 \\
(31 / 42)\end{array}$ & $\begin{array}{c}13 \\
(25 / 15)\end{array}$ & $\begin{array}{c}1.3 \\
(2.7 /-)\end{array}$ & $\begin{array}{c}1.3 \\
(1.6 /-)\end{array}$ & \\
\hline M7 & $\begin{array}{c}\mathbf{5 0}-\mathbf{5 8} \\
(350 / 1173)\end{array}$ & $\begin{array}{c}7.6 \\
(350 /-)\end{array}$ & $\begin{array}{l}\mathbf{1 0 - 2 8} \\
(29 /-)\end{array}$ & $\begin{array}{c}\mathbf{1 8} \\
(29 / 32)\end{array}$ & $\begin{array}{c}\mathbf{1 1 - 1 6} \\
(18 / 18)\end{array}$ & $\begin{array}{l}3.8 \\
(7 /-)\end{array}$ & $\begin{array}{l}\mathbf{1 5 - 1 6} \\
(17 / 19)\end{array}$ & $\begin{array}{c}\mathbf{1 9} \\
(18 / 33)\end{array}$ & $\begin{array}{c}\mathbf{8 - 1 2} \\
(12.4 /-)\end{array}$ & $\begin{array}{c}2.4 \\
(6.7 /-)\end{array}$ & $\begin{array}{c}\mathbf{1 2} \\
(11 / 90)\end{array}$ \\
\hline M8 & $\begin{array}{c}22.5 \\
(22 / 24)\end{array}$ & $\begin{array}{c}14 \\
(19 / 18) \\
\end{array}$ & & & & $\begin{array}{c}1.5 \\
(1.9 /-)\end{array}$ & $\begin{array}{c}\mathbf{9 0} \\
(99 / 111) \\
\end{array}$ & $\begin{array}{c}12 \\
(62.2 / 17) \\
\end{array}$ & $\begin{array}{c}2.35 \\
(2.4 /-) \\
\end{array}$ & $\begin{array}{c}\mathbf{2 . 3} \\
(2.42 /-)\end{array}$ & \\
\hline M9 & $\begin{array}{c}\mathbf{7 9} \\
(191 / 383)\end{array}$ & $\begin{array}{c}\mathbf{8 - 1 2} \\
(47 / 14) \\
\end{array}$ & & & $\begin{array}{c}6.6 \\
(9 / 8)\end{array}$ & $\begin{array}{c}\mathbf{0 . 9} \\
(1.4 /-)\end{array}$ & $\begin{array}{c}1.9 \\
(2.0 / 2.0)\end{array}$ & $\begin{array}{c}\mathbf{8 . 1} \\
(9 / 11)\end{array}$ & $\begin{array}{l}4.65 \\
(8 /-)\end{array}$ & $\begin{array}{c}2.2 \\
(4.0 /-)\end{array}$ & \\
\hline $\begin{array}{c}\text { Min/max } \\
\text { (avg) }\end{array}$ & $\begin{array}{c}\mathbf{2 2 / 8 0} \\
(55)\end{array}$ & $\begin{array}{l}\mathbf{6 . 5 / 1 8} \\
(12.8)\end{array}$ & $\begin{array}{l}\mathbf{1 0} / \mathbf{2 8} \\
(23.5)\end{array}$ & $\begin{array}{c}\mathbf{1 2 / 1 8} \\
(16)\end{array}$ & $\begin{array}{l}\mathbf{6 . 6 / 1 6} \\
(10.8)\end{array}$ & $\begin{array}{c}\mathbf{0 . 9 / 6 . 7} \\
(2.8)\end{array}$ & $\begin{array}{c}\mathbf{1 . 9} / \mathbf{9 0} \\
(21.2)\end{array}$ & $\begin{array}{l}\mathbf{8 . 1 - 1 9} \\
(12.4)\end{array}$ & $\begin{array}{c}1.2-12 \\
(3.1)\end{array}$ & $\begin{array}{c}\mathbf{1 . 0}-2.8 \\
(1.9)\end{array}$ & $\begin{array}{c}12 \\
(12)\end{array}$ \\
\hline
\end{tabular}

As evident from Table 4, the highest electric field intensity in porcelain in REF and M7 is under the conductor tie ( $\left.\mathrm{B}_{\text {porcelain}}\right)$. As the tie is at the same potential as the conductor, the electric field at point $\mathrm{A}$ is reduced. For all other models (without the conductor tie), highest electric field in the porcelain is observed at point $\mathrm{A}_{\text {porcelain }}$ under the conductor.

One would expect that the thickness of the porcelain in between the conductor and the grounded pin (Fig. 2 distance D) would be highly influential in defining the electric field in the porcelain, i.e., smaller distance between voltage and ground results in greater electric field intensity. Excluding REF and M7 as they include conductor ties, model M1 has the smallest porcelain thickness (Table 2, distance D) whereas M2 and M6 have the largest thickness. Nevertheless, M6 produces a larger value at point $\mathrm{A}_{\text {porcelain }}$ compared to $\mathrm{M} 1$ as well as twice as large value compared to its relatively similar model M2.

The largest variation between each model is observed in the pin cavity (Fig 7). As the participants were provided with intact samples of the insulator, insight on the design and materials in the cavity was limited as is evident from Fig. 8 (none of the participants broke the insulator sample for closer inspection). The insertion of the grounded pin also increased variation between models. Some models simulated the pin having a contact with the cork while other models left air gaps in 
between the materials. Not all models included the air pocket formed by the hole in the center of the cork (visible in Fig. 8). Moreover, the reference model inserted a layer of epoxy under the cork (in between the porcelain and cork). Also, the thickness of the epoxy surrounding the pin varied in each model. Only one model (M7) included threads and filler. All of these factors contribute to the large spread in simulated values at point C.

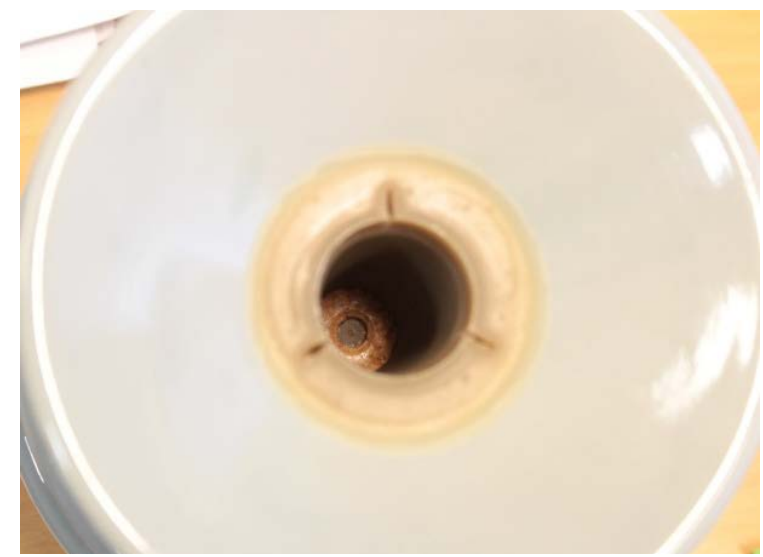

Fig. 8 - Pin cavity. Cork is visible at the bottom of the epoxy threads. Porcelain is slightly visible through the hole in the center of the cork.

Electric field profiles were plotted to aid in the comparison of simulation results (Fig. 9). These profiles display the electric field intensity along the center of the pin insulator. This profile does not describe maximum electric field at localized critical points but instead allows for comparison of each model as it portrays the field distribution along the same center line.

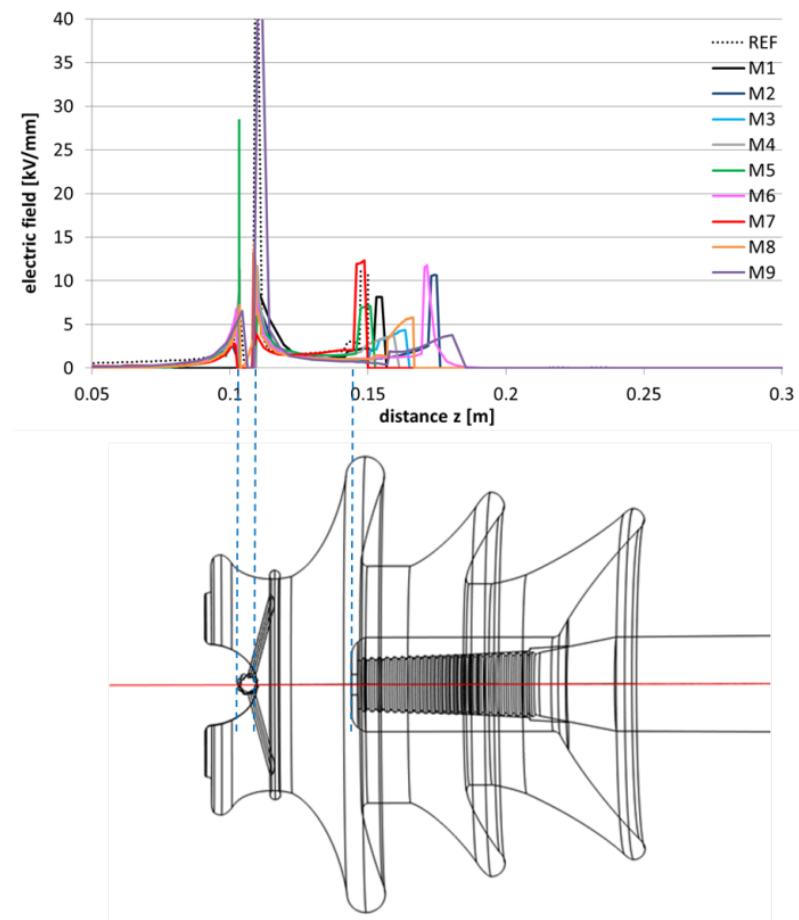

Fig. 9 - Electric field profiles. Electric field intensity is plotted along the red line in the center of the pin insulator.
Distance $z$ in Fig. 9 begins from the outer boundary of the simulation model (surrounding air), progresses through the conductor and porcelain into the pin cavity and along the center of the grounded pin until the opposite outer boundary of the simulation. All models display the same trends. Electric field increase in the vicinity of the live conductor $(\mathrm{z} \approx 0.1 \mathrm{~m})$ and drops to zero inside the conductor (zero potential difference, zero electric field). Field intensity once again peaks at the bottom surface of the conductor and decays when moving further into the porcelain. The next peaks in electric field are observed in the pin cavity $(\mathrm{z} \approx 0.14 \mathrm{~m})$. The onset and magnitude of these peaks depends on the thickness of porcelain (distance D) and material selection within the cavity as well as mesh details. Electric field once again drops to zero inside the grounded pin. Fig. 9 describes well how all the models represent the same physical sample but with divergent values despite the same task description. All models clearly exhibit the same trends but which values are most representative of true conditions?

\section{Discussion}

Even with the exclusion of the human factor in constructing the simulation model, the user still has a highly influential role in analyzing the results. For this reason, Table 4 also includes values computed by the software itself. In the table, the bold value is manually selected from the point of interest. The first value in the parentheses $(\mathrm{xx} /--)$ is the maximum electric field calculated on the surface of the material being investigated at the point of interest. The second value (-$/ \mathrm{xx}$ ) is the maximum electric field value calculated within the material volume. Thus, interfaces between two materials will have the same surface value. If the same material is investigated at several different points, the volume value will be the same. Manual selection refers to identifying the area of highest electric field based on the color scale in the $3 \mathrm{D}$ visualization. Zooming into this local region and selecting (clicking) a point of interest outputs a value for the selected coordinate.

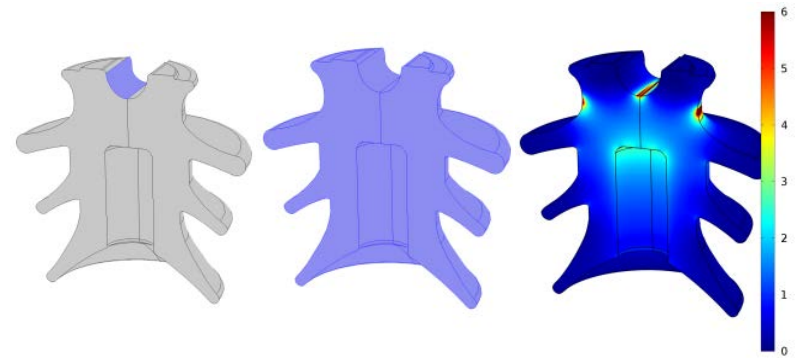

Fig. 10 - Calculation of electric field values. Left - surface maximum calculated from the surface identified in blue; middle - volume maximum calculated from entire volume; right - manual selection based on color scale.

A fully automated analysis relying purely on calculated maximum values can produce highly misleading data. For example, the mesh details and small geometry 
angles in M7 resulted in extremely small localized points of considerable electric field intensity. The maximum value within the volume of air surrounding the insulator is calculated as $1173 \mathrm{kV} / \mathrm{mm}$. Maximum electric field at the interface between the conductor and porcelain is calculated as $350 \mathrm{kV} / \mathrm{mm}$. Both of these values are clearly unrealistic and confined only to a specific point for which the software has calculated a misrepresentative value based on erroneous settings or conditions (defined by the user). Manual selection provides an approximate value much more representative of the investigated area. Such a significant difference between calculated and manually selected values is also a clear warning that the model requires further revision and refinement. In contrast, models with relatively similar calculated and selected values can be considered to be correctly constructed. However, even if the functionality of the model is feasible, this does not necessarily correlate to high representativeness of true conditions. For example, M1 has relatively similar dimensions as the reference, mesh quality is relatively good, and simulated values (manual selection vs. automated calculation) are relatively reasonable. Nevertheless, this model implements a considerably thicker epoxy layer surrounding the entire pin cavity than in reality. The previously discussed model M7 is a highly detailed model including threads, filler, and conductor strands as well as the side-tie which represents the voltage distribution along the design experienced in real operation. However in this model, the complexity gives rise to excessively small details which leads to computational errors at specific points. Thus, excessive detail can results in additional problems. M4 and M5 are similar relatively simplified models. Yet, these two models produce diverging values.

All of the models include factors defined by the user which lead to diverging end results. None of the investigated models (including the reference model) are true representations of the physical sample. All of the models do provide insight to the voltage and electric field distribution within the sample - nevertheless, a precise value depicting field intensity at a specific critical point cannot be obtained reliably.

\section{Conclusions}

Ten models of the same physical sample were constructed by users with varying levels of experience with simulations. All participants applied the same voltage stress across the live conductor and grounded pin, but varying physical dimensions, geometrical details, and implemented materials as well as mesh size lead to diverging results.

If the user relies blindly on simulated results, assessments can be highly misleading as evident from the excessively high field intensity values observed in this paper. Simulations can be used effectively as long as the user is able to discriminate between reasonable and unrealistic results. Understanding the influential factors and their severity, all of the models in this paper could be further refined to produce considerably more realistic results, starting from ensuring suitable mesh characteristics which forms the basis for the simulation's computations.

\section{References}

[1] Ensto, SDI30 Porcelain pin insulator, product card, 23.3.2015. Available online: http://products.ensto.com/catalog/product/15120/S DI30_ENG1.pdf

[2] Griesmer, A., "Size Parameters for Free Tetrahedral Meshing in COMSOL Multiphysics”, COSMOL Blog 30.1.2014. Available online: http://www.comsol.com/blogs/size-parametersfree-tetrahedral-meshing-comsol-multiphysics/ 